\title{
Research
}

\section{Patients' views of pay for performance in primary care:}

\author{
a qualitative study
}

\begin{abstract}
\section{Background}

Many countries use pay-for-performance

schemes to reward family practices financially for achieving quality indicators. The views of patients on pay for performance remain largely unexplored.
\end{abstract}

\section{Aim}

To gain the views of family practice patients on the United Kingdom pay-for-performance Quality and Outcomes Framework (QOF).

\section{Design and setting}

Interviews with 52 patients were conducted in 15 family practices across England. All patients had at least one long-term condition that had been diagnosed before the introduction of the QOF in 2004

\section{Method}

Semi-structured interviews analysed using open explorative thematic coding

\section{Results}

Few patients had heard of the QOF or had noticed changes to the structure or process of their care. However, where they were noted, changes to consultations such as increased use of computers and health checks initiated by the GP or practice nurse were seen as good practice. The majority of patients were surprised to hear their practice received bonuses for doing simple things'. Some patients also raised concerns over potential unintended consequences of pay-forperformance frameworks, such as a reduced focus on non-incentivised areas.

\section{Conclusion}

This study adds a unique patient perspective to the debate around the impact of pay-for-

performance schemes and consequences on patient care. Patients' views, experiences, and concerns about pay for performance mostly chime with previously described opinions of primary care staff. Patient surprise and concern around incentivising basic processes of care shows how patient views are vital when monitoring and evaluating a scheme that is designed to improve patient care.

\section{Keywords}

patients; pay for performance; qualitative research

\section{INTRODUCTION}

Pay-for-performance schemes financially reward family practices for achieving targets attached to quality indicators. These schemes are increasingly common worldwide and have been used in the United States of America ${ }^{1,2}$ and the UK in particular. ${ }^{3,4}$ In 2004, the Quality and Outcomes Framework (QOF) was introduced in the UK as a pay-for-performance scheme for general practices, whereby over $20 \%$ of GPs' income is based on meeting targets relating to clinical and organisational quality indicators. ${ }^{5}$ The QOF has led to equitable improvements in quality standards across practices and patient outcomes in a number of incentivised conditions. ${ }^{6-8}$ However, it has also been criticised as inflexible and potentially damaging to holistic doctorpatient relationships,, 10 and may lead to a diminished focus on non-incentivised clinical areas. ${ }^{11}$

A qualitative study by Maisey et al explored English GPs' and practice nurses' views on the effects of pay for performance in primary care and found that staff believed consistency and recording of care had improved for conditions that were incentivised in the scheme, but not for nonincentivised conditions. ${ }^{12}$ An early ethnographic study of the impact of the QOF found that GPs were generally positive about it, with little threat to internal motivation of their core values. ${ }^{10}$ However, other qualitative research with family doctors and nurses highlighted concerns

KL Hannon, MSc, research associate;

SM Campbell, PhD, reader in primary care, Health Sciences Research Group - Primary Care, School of Community Based Medicine, University of

Manchester. HE Lester, MB, BCH, MD, professor of primary care, Primary Care Clinical Sciences,

School of Health and Population Sciences,

University of Birmingham.

\section{Address for correspondence}

Helen E Lester, Primary Care Clinical Sciences, School of Health and Population Sciences, about a decline in relational continuity of care, deskilling of doctors due to enhanced nurse roles, and the emerging presence of a dual agenda in consultations, due to the need to prioritise and record incentivised aspects of care alongside addressing the patient's concerns and reasons for attendance. ${ }^{13}$ Patients' perceptions of the quality of a primary care consultation have been found to be based on the doctor's competence and perceived empathy or caring. ${ }^{14-16}$

To the authors' knowledge, there has been no research that has explored whether changes in the quality of care as a consequence of pay-for-performance schemes are recognised or valued by patients.

This paper presents the findings of a study that aimed to explore the views of patients on the existence, impact, and implementation of the UK pay-forperformance scheme in primary care.

\section{METHOD}

Patients were recruited from a nationally representative sample of 26 family practices in 12 primary care trust areas in England. These organisational units were selected to be representative in terms of size and deprivation. Practice managers were asked to select 20 patients randomly who were on one of 13 QOF long-term condition disease registers lasthma, cancer, chronic obstructive pulmonary disease, diabetes, stroke, heart failure, serious mental illness,

University of Birmingham, Edgbaston, B15 2TT.

E-mail: h.e.lesterabham.ac.uk

Submitted: 20 November 2011; Editor's response: 7 December 2011; final acceptance: 16 December 2011.

\section{CBritish Journal of General Practice}

This is the full-length article (published online $30 \mathrm{Apr}$ 2012) of an abridged version published in print. Cite this article as: Br J Gen Pract 2012; DOI: 10.3399/bjgp12X641438. 


\section{How this fits in}

Previous studies have gained the views of GPs and practice nurses on the effects of pay for performance; however, the views of patients have not been sought. This study suggests that few patients with long-term conditions were aware of the Quality and Outcomes Framework or had noticed changes to the structure or process of their care, despite the significant cost of the scheme. The majority of patients were surprised that their practices received payments for achieving basic standards of care. Changes within consultations, such as increased use of computers and practice-initiated requests for healthprevention information, were, contrary to received wisdom, seen as markers of good care by some patients.

hypertension, hypothyroid, atrial fibrillation, epilepsy, cardiovascular disease primary prevention, and chronic kidney diseasel and had had their condition prior to the introduction of the QOF in 2004. People on the palliative care, learning disability, or obesity registers were not included because of concerns about burdening patients inappropriately or contacting people in domains where the only indicator was a patient register. After review by a clinician to ensure that patients were not acutely unwell or particularly distressed at the time of recruitment, patients were invited by a letter from the practice to take part in a semi-structured interview.

Interviews were conducted by two health service researchers and a clinician and health service researcher who presented herself in her researcher role to patients, to explore the views of patients around pay for performance in primary care. The majority of interviews were conducted in the patient's home, between January and April 2011. The topic guide explored patients' knowledge of the QOF and opinion of its impact and how it may have affected the care they received since 2004. A standard description of the QOF was agreed a priori by the research team (Box 1).

\section{Box 1. Description of the Quality and Outcomes Framework (QOF)}

- The QOF is a pay-for-performance scheme where extra money is paid for carrying out and achieving certain tasks.

- The money received by the practice depends on the number of people with that condition who received the specified care.

- Money is paid to the practice but some of it is used to increase the salary of GP partners.

- If the practice provides the pre-specified care to the majority of the patients with the long-term condition, then the QOF income provides about $20 \%$ of a GP's take-home pay.
Each patient was also told the indicators in their own clinical domain as an example of the type of care they might have experienced. The interviews were digitally recorded and fully transcribed.

Analysis was conducted in parallel with the interviews and was inductive, using components of thematic analysis that were in line with modified grounded theory. Thematic categories were identified in initial interviews and then explored in subsequent interviews. Differences in views between people with different conditions and different ages were actively sought, and disconfirming evidence was used to modify emerging themes. The main categories were then compared across interviews and reintegrated into common themes. ${ }^{17,18}$ Interview transcripts were read, annotated, and categorised independently by the three researchers, to increase reliability, and subsequently discussed by the researchers as a group. As this study was explorative, not theoretical, open coding was used rather than axial or selective coding..$^{19}$ The authors agreed theoretical saturation was achieved when no new ideas emerged during the final interviews with patients with each represented long-term condition.

\section{RESULTS}

Fifteen of the 26 practices agreed to take part. These practices were in the following geographical areas: Bath, Bristol, Somerset, Enfield, Essex, Haringey, Nottingham, Huddersfield, West Yorkshire, Oldham, Bury, and Cheshire. Each practice wrote to patients on one of the 13 disease registers. Fifty-two patients from 15 practices were interviewed. No patients with serious mental illness volunteered to take part in this research. Participants were aged between 32 and 90 years (mean age 64 years), and included 25 males and 27 females. All patients had their diagnosis prior to the introduction of the QOF in 2004. Patient demographics are shown in Table 1.

Five key themes relevant to the aims and objectives of this study were identified: the value of financial incentives in primary care; payment for simple tasks; impact on received care; the use of computers; and unintended consequences.

\section{The value of financial incentives in primary care}

The majority of patients liked and trusted their GP and believed that poor-quality care would be the exception rather than the rule. Few patients had heard of the QOF prior to the interview. After listening to a standardised description, the majority of 


\section{Table 1. Patient demographics}

\begin{tabular}{|c|c|c|c|c|}
\hline Patient number & Sex & Age, years & Condition & Ethnicity \\
\hline 1 & Female & 60 & Hypothyroid & White European \\
\hline 2 & Male & 82 & Diabetes & White British \\
\hline 3 & Female & 72 & Hypothyroid & Asian \\
\hline 4 & Female & 64 & Hypertension & White British \\
\hline 5 & Female & 57 & Hypertension & White British \\
\hline 6 & Female & 62 & Hypertension & White British \\
\hline 7 & Female & 60 & Hypothyroid & White British \\
\hline 8 & Male & 50 & Diabetes & Black/Black British \\
\hline 9 & Male & 38 & Diabetes & White British \\
\hline 10 & Male & 90 & Cancer & White British \\
\hline 11 & Male & 63 & Cancer & White British \\
\hline 12 & Female & 61 & Cancer & Asian \\
\hline 13 & Female & 68 & Cancer & White British \\
\hline 14 & Male & 78 & Diabetes & White British \\
\hline 15 & Male & 61 & Stroke & White British \\
\hline 16 & Female & 76 & Heart failure & White British \\
\hline 17 & Male & 79 & CKD & White British \\
\hline 18 & Female & 70 & Hypertension & White British \\
\hline 19 & Female & 59 & CKD & White British \\
\hline 20 & Female & 81 & Diabetes & White British \\
\hline 21 & Male & 57 & Stroke & White British \\
\hline 22 & Male & 80 & Stroke & White British \\
\hline 23 & Female & 60 & Stroke & White British \\
\hline 24 & Male & 79 & Stroke & White British \\
\hline 25 & Male & 71 & Heart failure & White British \\
\hline 26 & Female & 57 & Heart failure & White European \\
\hline 27 & Female & 83 & Heart failure & White British \\
\hline 28 & Male & 76 & COPD & White British \\
\hline 29 & Male & 54 & Hypertension & White British \\
\hline 30 & Female & 85 & Heart failure & White British \\
\hline 31 & Female & 62 & CKD & White British \\
\hline 32 & Female & 64 & CKD & White British \\
\hline 33 & Female & 50 & CKD & White British \\
\hline 34 & Female & 59 & Heart failure & White British \\
\hline 35 & Female & 43 & Hypertension & White British \\
\hline 36 & Female & 32 & Diabetes & White British \\
\hline 37 & Male & 41 & Hypertension & White British \\
\hline 38 & Female & 40 & Hyperthyroid & White American \\
\hline 39 & Male & 67 & Cancer & White British \\
\hline 40 & Male & 61 & Asthma & White British \\
\hline 41 & Female & 86 & CVD pp & White British \\
\hline 42 & Female & 65 & Diabetes & White British \\
\hline 43 & Male & 86 & Diabetes & White British \\
\hline 44 & Male & 77 & Diabetes & White British \\
\hline 45 & Female & 45 & Hypertension & Asian \\
\hline 46 & Female & 59 & Hypertension & White British \\
\hline 47 & Male & 44 & $\mathrm{AF}$ & White British \\
\hline 48 & Female & 60 & Epilepsy & White British \\
\hline 49 & Male & 87 & Epilepsy & White British \\
\hline 50 & Female & 62 & Epilepsy & White British \\
\hline 51 & Male & 68 & Epilepsy & White British \\
\hline 52 & Male & 78 & Asthma & White British \\
\hline
\end{tabular}

participants thought that pay for performance was not an appropriate tool to promote quality of care:

'Personally I think it's wrong. I think they should deliver the quality of care because it's the professional thing to do.' (patient 29)

you would like to think they were doing it because they thought it was necessary and a part of your care more than possibly, oh, well, if we do him we get extra pay. I don't like the idea of that.' (patient 52)

If there are minimum standards of care then that should be a minimum standard of care regardless of whether you're given extra for it.' (patient 35)

A small number of participants $(n=8)$ believed that it would be more effective to penalise GPs for poor-quality care. This often reflected the policy in their own workplace:

'There should be a disciplinary procedure, not incentives. Pull your socks up, or written warnings ...' (patient 13)

I've got motivation to do my job properly and if a GP hasn't got the same motivation then it will soon be found out and the patients could soon make it very difficult for that GP and have him struck off.' (patient 29)

However, a similar small number $(n=6)$ of participants in this study were reassured that there was such a quality tool in place. They liked the idea that all GPs and nurses were encouraged to follow up-to-date, evidence-based guidance. This group believed that any increase in the quality of care that may result from the scheme was worth the additional payment to GPs:

I don't mind because if it means that I get better care, then it's better for me in the long run.' (patient 9)

'If it means that you get a consistent quality of care ... if you get guidance that says we've got this so you need to do these tests, and when these tests are done then you can get paid, then if that helps them ... then I don't mind if that's incentivised in that way. (patient 38)

\section{Payment for simple tasks}

Most participants were surprised to hear their practice was paid money for 'simple things'. Many thought that GPs were adequately paid and should not be financially rewarded for carrying out clinical activities that were believed to be a fundamental part of a GP's role and duty of care:

'I certainly didn't realise that you got an extra payment for taking somebody's blood 
pressure, good heavens.' (patient 42)

'Personally I think it's wrong. My feeling is that the GP there is to care for your health. If taking your blood pressure and giving you flu jabs and all that sort of thing is part of caring for your health, and that's what he should do. Why should he get paid extra for it? (patient 52)

Three participants, who believed that incentives were worthwhile, suggested that they should be in place for more complex tasks:

When you have ... somebody comes in with something that is really complicated, then that's when they earn their money. (patient 52

\section{Impact on received care}

When considering the impact on the care received for their own long-term condition, few participants, regardless of their particular condition, had noticed any changes in the structure or process of care following the introduction of the QOF in 2004. This suggests that the majority of practices had not made significant, noticeable changes to the management of long-term conditions during the time frame of the payfor-performance scheme, or that changes were introduced to the administrative elements of primary care such as registers and recall systems:

I don't think it has changed at all because I've been on that medication and I've always had a review, had my blood pressure checked every 6 months.' (patient 19)

However, just under a quarter of those interviewed ( $n=12)$, with six different index conditions, had noticed some changes since 2004, such as an increased likelihood of being called in for a blood test or medication review:

In the last 6 or 7 years, they sent me more letters out, you know, to get me up here. (patient 40)

'There are blood pressure checks, urine specimen, blood specimens annually which didn't use to happen before. I suppose I have to say yes ... it has made a difference. (patient 6)

When considering doctor-initiated elements of care, patients were asked to recall if their GP or practice nurse had asked them a question about their health that seemed unrelated to the reason why they had consulted them. Five people remembered being asked questions around smoking status or weight in consultations unrelated to such issues. However, these patients described how they valued these unrelated health checks, and believed that it demonstrated high-quality care from their practice:

'They also talk about smoking interventions and stuff like that. All that sort of thing can only be beneficial I am sure.' (patient 21)

\section{The use of computers}

The majority of participants recognised that the practice staff tended to spend more time looking at the computer screen than they used to. Many patients viewed this positively, especially if they were able to see the screen and openly discuss their information; for example, tracking their own blood results over time. They were reassured that their GP or practice nurse had access to their medical records and received prompts to follow evidence-based guidance for their condition:

$\therefore$ this nurse, and she's forever sort of saying, "Oh, let's see what it was last time", it's quite exciting, "Let's see if this has got better". So she's constantly looking at the screen, but then I would expect her to.' (patient 23)

... sometimes they switch the screen so I can see it as well and that gives me some reassurance ... and also it just gives you an insight of your own record, because that is your information.' (patient 8)

However, two patients thought that reliance on computers had a negative impact on the doctor-patient relationship in their consultation. They felt that the GP and practice nurse spent too much time looking at the screen rather than listening to their needs:

'Sometimes you feel like they're not listening don't you? And it's just ... going through the motions ...' (patient 9)

\section{Unintended consequences}

A minority $(n=5)$ of patients were concerned that their practice may only focus on incentivised areas, to the detriment of nonincentivised aspects of care. For example, they were concerned that GPs might ignore emotional aspects and instead focus on physical aspects of their health:

I know what it's like to gear your operation 
towards hitting targets, you ignore some of the other issues.' (patient 46)

Patients $(n=6)$ also expressed worries that GPs would automatically try to meet the target without considering what was best for the patient. Pay-for-performance schemes could eat into consultation time, leaving less time for patients to discuss their individual needs and experiences:

'On his performance indicator it will be just ticked that he's prescribed $x$ amount of medication for people with diabetes, but it's not necessarily the one that's most appropriate.' (patient 8)

\section{DISCUSSION}

\section{Summary}

This study adds to the literature around the impact of the QOF and provides an insight into what patients think of pay for performance in primary care. Patients felt that financial incentives should not be attached to achieving simple tasks. Few patients had noticed any changes in the structure or process of their care since the introduction of the QOF in 2004, other than an increase in letters of invitation for recall and the use of computers in the consultation. Where it had been noted, patients appeared to value the ability to view their notes or results on the screen. Practitioner-initiated requests to check health issues unrelated to the presenting complaint were also viewed as good practice by the small minority of patients who noticed such requests. A small number of patients were worried that pay for performance may lead to poorer quality of care in non-incentivised areas, or patientcentred care, which were seen as integral to the quality of their care.

\section{Competing interests}

At the time this study was conducted, Helen E Lester and Stephen M Campbell were contracted to the National Institute for Health and Clinical Excellence to provide advice on removal of indicators and pilot new indicators for the Quality and Outcomes Framework.

\section{Ethical approval}

Ethical approval was obtained from the North West 4 Research Ethics Committee: Liverpool North (10/H1001/5).

\section{Acknowledgments}

The authors wish to thank Evangelos Kontopantelis and the patients and staff in all participating pilot practices.

\section{Discuss this article}

Contribute and read comments about this article on the Discussion Forum: http://www.rcgp.org.uk/bjgp-discuss

\section{Strengths and limitations}

Previous research has examined GP opinions on the effects of pay for performance on primary care. However, to the authors' knowledge, there has been no qualitative study of patients' views on payfor-performance schemes.

This study incorporates the views of patients in a nationally representative sample of general practices in England. However, the generalisability of the study is limited by the participants' age and possible responder and recall bias, making it possible that patients' views were more focused on current perceptions rather than pre-2004. The researchers chose to talk to people with long-term conditions as they are the most frequent users of primary care, and would therefore be most able to comment on potential differences in care before and after the introduction of the QOF. However, due to the nature of these long-term conditions, the majority of patients were aged over 50 years, with a mean age of 64 years. Although the views of those with 12 of 13 long-term conditions in the QOF are represented, no patients with serious mental illness agreed to participate in this study and this may represent an area for future research. The views of patients with conditions that are not incentivised would further contextualise the findings of this study, as would those of a younger and more ethnically diverse sample. ${ }^{20}$

\section{Comparison with existing literature}

Pay for performance in primary care was introduced into the UK with the aim of rewarding quality patient care. However, research has shown that it may have a negative impact on unmeasured aspects of care, such as the quality of consultations ${ }^{21}$ and non-incentivised aspects of care. ${ }^{11}$

The concern, of a minority of patients in this study, that GP may prioritise targets over personalised care resonates with previous findings where some GPs felt that pay for performance had changed the emphasis away from listening to patients' concerns. ${ }^{12,13}$ In recent qualitative studies, evidence of unintended consequences has also been found in relation to indicators including the presence of 'measure fixation', where inappropriate attention on isolated aspects of care or a dual agenda can conflict with patient-centred care. ${ }^{22,23}$ This study also adds to the concerns that non-incentivised conditions or aspects of care may receive less attention by practice staff. ${ }^{10,11}$ This step away from a holistic approach may affect aspects of care that are seen as important to patients, such as a GP's competence, empathy, and listening skills. ${ }^{14}$

The QOF encourages the use of evidencebased templates by practice staff when diagnosing and treating patients with an incentivised long-term condition. Templates in the electronic medical records are valued by practice staff as reminders of evidencebased care for incentivised conditions. ${ }^{11}$ Prompts on these templates for doctorinitiated elements of care, such as questions around weight or smoking were, however, also valued by the minority of patients in this study who noticed the introduction of such measures. Although the QOF has led to a more biomedical form of medical care, ${ }^{24,25}$ these doctor-led questions around wider care were interpreted by these patients as caring and proactive. Previous assertions that a GP's ability to do two things at once lbe 
both patient centred and target focused) was optimistic at best, and more likely to be detrimental to care, may themselves be overly pessimistic. ${ }^{26-27}$

The increased use of computers described by patients has also been previously reported by GPs and practice nurses. 13,21,23,28,29 However, the present finding that many patients appear to value the use of computers in consultations contrasts with GPs' beliefs that this reliance can reduce the quality of interpersonal communication in the consultation. ${ }^{24}$ Although computer use can be negatively related to some aspects of communication, such as eye contact with the patient, this study found that patients can be reassured by the availability of their records in obvious electronic form, the opportunity to see how their illness is or is not progressing, and the ability to discuss their health outcomes in detail.

This study also adds to the increasing evidence base that non-incentivised conditions or aspects of care may receive less attention by practice staff.10,11 GPs have previously stated that time pressures meant they prioritised the financially incentivised issues over other aspects of care.22,23 This was described as 'tunnel vision' and suggests that patients with non-incentivised conditions may be at risk of poorer-quality care, an issue now echoed by some patients.

\section{Implications for practice and research}

A number of studies have called for ongoing monitoring and evaluation of pay-for- performance schemes to determine the effectiveness of financial incentives and their possible unintended effects on quality of care. ${ }^{22,23,30,31}$ This study moves the pay-forperformance debate forward by providing a patient perspective that has implications for both practitioners and policy makers.

A key recurring concern in the literature is whether financial incentives adversely affect care by reducing the time for patients in consultations, failing to address patients' concerns, or impairing continuity of care. 13,22,32,33 This study suggests that the majority of patients do not believe that pay for performance has had a negative effect on their experience of care. The use of computers and GP-initiated health checks were seen by some patients as reassuring and valued additions to the consultation. However, the finding that the QOF may have had little perceived impact on the structure or process of primary care for patients with long-term conditions, and patients' surprise at the financial incentivisation of simple processes, perhaps supports the current drive in the UK towards the development of a more outcomes-focused framework. ${ }^{34}$

This study suggests that patients' views and experiences of pay for performance mostly agree with the evidence base on pay for performance and with the opinions and concerns of general practice staff. By emphasising that few patients had heard of the QOF and concerns with incentivising care, it suggests that patients' views are vital when monitoring and evaluating a scheme designed to improve patient care. 


\section{REFERENCES}

1. Rosenthal MB, Frank RG, Li Z, et al. Early experience with pay for performance: from concept to practice. JAMA 2005; 294(14): 1788-1793.

2. Rosenthal M, Adams DR. Pay-for-performance. Will the latest payment trend improve care? JAMA 2007; 297(7): 740-744.

3. Lester H, Campbell S. Developing Quality and Outcomes Framework indicators and the concept of 'QOFability'. Qual Prim Care 2010; 18(2): 103-109.

4. Gillam S, Siriwardena N (eds). The Quality and Outcomes Framework: transforming general practice. Oxford: Radcliffe Publishing, 2010.

5. Roland M. Linking physician pay to quality of care: a major experiment in the UK. New Engl J Med 2004; 351(14): 1448-1454.

6. Campbell SM, Reeves D, Kontopantelis $\mathrm{E}$, et al. Improvements in clinical quality in English primary care before and after the introduction of a pay for performance scheme. N Engl J Med 2007; 357(2): 181-190.

7. Campbell SM, Reeves D, Kontopantelis E, et al. Impact of pay-for-performance on quality of English primary care: interrupted time series analysis. N Engl J Med 2009; 361(4): 368-378.

8. Doran T, Fullwood C, Kontopantelis E, Reeves D. Effect of financial incentives on inequalities in the delivery of primary clinical care in England: analysis of clinical activity indicators for the quality and outcomes framework. Lancet 2008; 372(9640): 728-736.

9. Heath I, Hippisley-Cox J, Smeeth L. Measuring performance and missing the point? BMJ 2007; 335(7629): 1075-1076.

10. McDonald R, Harrison S, Checkland K, et al. Impact of financial incentives on clinical autonomy and internal motivation in primary care: ethnographic study. BMJ 2007; 334(7608): 1357

11. Doran T, Kontopantelis E, Valderas JM, et al. Effect of financial incentives on incentivised and non-incentivised clinical activities: longitudinal analysis of data from the UK Quality and Outcomes Framework. BMJ 2011; 342: d3590.

12. Maisey $\mathrm{S}$, Steel $\mathrm{N}$, Marsh $\mathrm{R}$, et al. Effects of payment for performance in primary care: qualitative interview study. J Health Serv Res Policy 2008; 13(3): 133-139.

13. Campbell SM, McDonald $\mathrm{R}$, Lester $\mathrm{H}$. The experience of pay for performance in English family practice: a qualitative study. Ann Fam Med 2008; 6(3): 228-234.

14. Mercer SW, Cawston PG, Bikker AP. Quality in general practice consultations; a qualitative study of the views of patients living in an area of high socio-economic deprivation in Scotland. BMC Fam Pract 2007; 8: 22

15. Wensing M, Jung HP, Mainz J, et al. A systematic review of the literature on patient priorities for general practice care. Part 1: description of the research domain. Soc Sci Med 1998; 47(10): 1573-1588.

16. Cheraghi-Sohi S, Hole AR, Mead N, et al. What patients want from primary care consultations: a discrete choice experiment to identify patients' priorities. Ann Fam Med 2008; 6(2): 107-115
17. Silverman D. Qualitative research: theory, method and practice. London: Sage, 1997.

18. Neuman WL. Social research methods: qualitative and quantitative approaches. Needham Heights: Allyn and Bacon, 2000

19. Strauss A, Corbin J. Basics of qualitative research. London: Sage, 1990.

20. Casalino LP, Elster A. Will pay-for-performance and quality reporting affect health care disparities? Health Aff 2007; 26(3): w405-414.

21. Steel N, Willems S. Research learning from the UK Quality and Outcomes Framework: a review of existing research. Qual Prim Care 2010; 8(2): 117-125.

22. Lester $\mathrm{H}$, Hannon $\mathrm{K}$, Campbell $\mathrm{S}$. Identifying unintended consequences of quality indicators: a qualitative study. BMJ Qual Saf 2011; 20(12): 1057-1061.

23. Campbell SM, Kontopantelis E, Hannon K, et al. Framework and indicator testing protocol for developing and piloting quality indicators for the UK Quality and Outcomes Framework. BMC Fam Pract 2011; 12: 85

24. Cheraghi-Sohi S, Bower P, Mead N, et al. What are the key attributes of primary care for patients? Building a conceptual 'map' of patient preferences. Health Expect 2006; 9(3): 275-84

25. Checkland K, Harrison SR, McDonald ER, et al. Biomedicine, holism and general medical practice: responses to the 2004 General Practitioner contract. Sociol Health Illn 2008; 30(5): 788-803.

26. Checkland K, Harrison S. The impact of the Quality and Outcomes Framework on practice organisation and service delivery: summary of evidence from two qualitative studies. Qual Prim Care 2010; 18(2): 139-146.

27. Checkland K, McDonald R, Harrison S. Ticking boxes and changing the social world: data collection and the new UK general practice contract. Soc Policy Adm 2007; 41(7): 693-710

28. Booth N, Robinson P, Kohannejad J. Identification of high-quality consultation practice in primary care: the effects of computer use on doctor-patient rapport. Inform Prim Care 2004; 12(2): 75-83.

29. Short D, Frischer M, Bashford J. Barriers to the adoption of computerised decision support systems in general practice consultations: a qualitative study of general practitioners' perspectives. Int J Med Inform 2004; 73(4): 357-362.

30. Petersen LA, Woodard LD, Urech $T$, et al. Does pay for performance improve the quality of care? Ann Intern Med 2006; 145(4): 265-272.

31. Snyder L, Neubauer RL. Pay-for-performance principles that promote patientcentered care: an ethics manifesto. Ann Intern Med 2007; 147(11): 792-794.

32. Harrison S, Smith C. Trust and moral motivation: redundant resources in health and social care? Policy Polit 2004; 32(3): 371-86

33. Gravelle $H$, Sutton M, Ma A. Doctor behaviour under a pay for performance contract: further evidence from the quality and outcomes framework. CHE Research Paper. York: Centre for Health Economics, University of York, 2008.

34. Department of Health. Liberating the NHS: transparency in outcomes - a framework for the NHS. London: Department of Health, 2010. 